To the Editors:

\title{
Clinical features of leptospirosis: a prospective descriptive study at the National Hospital of Sri Lanka (NHSL) in 2007
}

The prevalence of leptospirosis in Sri Lanka has gradually increased since the earliest reports in 1953 [1]. Statistics show that in 2007 about $10 \%$ of medical ICU admissions were due to leptospirosis, and $65 \%$ of them died from complications. Regular evaluation of the clinical features of leptospirosis is important for early detection and accurate management of the disease [1]. The objective of this study is to describe clinical features and outcomes of patients with confirmed leptospirosis admitted to the National Hospital of Sri Lanka (NHSL).

Ours was a prospective study of 45 patients with confirmed leptospirosis admitted to a medical unit at the NHSL from 1 January to 31 December 2007. The entry criteria were: clinically compatible illness, and presence of an anti-leptospira IgM antibody titre of $>1: 1600$ in a single sample or a four-fold rising titre of 1:100 - 1:1600 in paired samples. The demographic characteristics, clinical profile, and outcomes were noted.

Of 97 patients who were investigated for leptospirosis on clinical suspicion, 45 were serologically confirmed. The majority gave a history of exposure to contaminated water, and a significant percentage were those involved in manual (35.5\%) and agricultural work $(33.3 \%)$. All presented with a monophasic febrile illness, and the most frequent clinical features were fever, myalgia, jaundice, and conjunctival injection (table 1).

All patients had neutrophil leucocytosis, thrombocytopenia, and evidence of renal and hepatic involvement. Eleven developed acute renal failure and haemodialysis was indicated for 7. During the course of the illness 14 developed acute lung injury and 13 died. 8 of them did not receive ventilatory support due to the non-availability of beds in the intensive care unit.

The patients were mainly 'high risk' occupational groups even though a previous Sri Lankan study showed that leptospirosis had shifted from an 'occupational disease' to an 'environmental disease' [1]. The classical biphasic febrile illness is described as a common presentation in previous studies [1-4]. However, all our patients had a monophasic illness. The frequency of jaundice, renal involvement, leucocytosis with neutrophilia and thrombocytopenia were strikingly higher than previously reported [2]. Fever with polymorphoneuclear leucocytosis, thrombocytopenia, elevated serum creatinine and transaminases should alert the clinician to the possibility of leptospirosis in situations where demonstration of leptospira by dark ground microscopy or serology are not readily available.

In previous studies, acute renal failure was considered the commonest fatal complication [1-4], but this did not cause any deaths in our series, possibly due to aggressive management with haemodialysis. The commonest fatal complication in this study ( $92 \%$ of mortality) was acute lung injury which has not been recognised as a common complication of leptospirosis in previous studies [1-4].

Since this study was conducted in a national referral centre, there is a strong likelihood of inclusion of more complicated cases. We need a larger multicentre study to validate our findings and to develop criteria based on clinical features and readily available laboratory tests to make an early diagnosis. Research should also be directed at identifying predictors of acute lung injury and early interventional options. Table 1. Clinical and laboratory features
of the 45 leptospirosis cases

\begin{tabular}{lcc}
\hline Clinical feature & $n$ & $\%$ \\
\hline Fever & 45 & 100 \\
Myalgia & 42 & 93.3 \\
Jaundice & 44 & 97.7 \\
Conjunctival injection & 31 & 68.8 \\
Neck stiffness & 1 & 02.2 \\
Leucocytosis $\left(>11.0 \times 10^{9} / 1\right)$ & 45 & 100 \\
Neutrophilia $\left(>7.5 \times 10^{9} / 1\right)$ & 45 & 100 \\
Thrombocytopenia $\left(<150 \times 10^{9} / 1\right)$ & 45 & 100 \\
Lymphopenia $\left(<1.5 \times 10^{9} / 1\right)$ & 13 & 28.8 \\
Elevated serum creatinine & 45 & 100 \\
Hematuria & 36 & 80.0 \\
Elevated serum transaminases & 45 & 100 \\
\end{tabular}

Table 2. Complications of leptospirosis $(n=45)$

\begin{tabular}{lcc}
\hline Complication & $\begin{array}{c}\text { Total } \\
n(\%)\end{array}$ & $\begin{array}{c}\text { Death } \\
n(\%)\end{array}$ \\
\hline Acute renal failure & $11(24.4)$ & - \\
Acute lung injury & $14(31.1)$ & $13(28.8)$ \\
Myocarditis & $7(15.5)$ & $2(4.4)$ \\
Meningitis & $1(2.2)$ & - \\
Encephalopathy & $2(4.4)$ & - \\
\hline
\end{tabular}




\section{References}

1. Ramachandran S, Rajapakse CAN, Perera MVF. Changing patterns in leptospirosis in Sri Lanka. Ceylon Medical Journal 1974; 4: 142-9.

2. Jaureguiberry S, Roussel M, Brinchault RG, Gacouin A, Le Meur A, et al. Clinical presentation of leptospirosis: a retrospective study of 34 patients admitted to a single institution in metropolitan France. European Journal of Clinical Microbiology and Infection 2005; 11: 391-4.
3. Magarita RR, Adrian CP. Clinical and laboratory profile of leptospirosis: an analysis of twenty six cases at Quirino Memorial Medical Centre admitted in August 1999. Philippine Journal of Microbiology and Infectious Diseases 2001; 30: 18-21.

4. Gerard V, Edmilao MI, Cordero CP, Valdez JR, Valdez JR. Predictors of oliguria and complications / mortality among patients with acute renal failure due to leptospirosis a PGH experience. Philippine Journal of Internal Medicine 2000; 38: $235-42$.

S A C U Gunawardhana and K H Sellahewa, National Hospital of Sri Lanka, Colombo.

Correspondence: KHS, e-mail: <kolithah@eureka.lk>. Received 4 March 2008 and revised version accepted 13 August 2008. Conflicts of interest: none declared. 